\title{
CISTO ÓSSEO SIMPLES - RELATO DE CASO CLÍNICO
}

\begin{abstract}
Anne Lopes Oliveira*, Jandson Michel Santos**, Adriano Assis**, Sílvia Regina de Almeida Reis***, Alena Ribeiro Alves Peixoto Medrado***

Autor correspondente: Alena Ribeiro A. P. Medrado - E-mail: alenamedrado@hotmail.com

* Acadêmica do 100 semestre do Curso de Odontologia da Escola Bahiana de Medicina e Saúde Pública

** Residência Universitária em Cirurgia Bucomaxilofacial da Escola Bahiana de Medicina e Saúde Pública

*** Professora Adjunto do Curso de Odontologia da Escola Bahiana de Medicina e Saúde Pública
\end{abstract}

\section{Resumo}

A Organização Mundial de Saúde classifica o cisto ósseo simples como uma lesão não neoplásica relacionada aos ossos, sendo definida como um cisto intraósseo que apresenta uma cápsula tênue. A sua etiologia permanece desconhecida, sendo que a explicação mais aceita estaria relacionada à história de trauma. É, na maioria dos casos, clinicamente assintomático e o diagnóstico muitas vezes é estabelecido através do exame radiográfico de rotina. O objetivo do presente trabalho é relatar um caso clínico de cisto ósseo simples, em região mandibular esquerda em um paciente jovem, submetido a exames imaginológicos para fins de acompanhamento do tratamento ortodôntico. O paciente compareceu a um Serviço de Cirurgia e Traumatologia Bucomaxilofacial apresentando lesão radiolúcida de grandes proporções unilocular, circunscrita, em região mandibular esquerda. Não relatou sintomatologia dolorosa ou tumefação significativa. Foi realizada biópsia excisional e os achados histopatológicos exibiram tecido ósseo associado a uma fina membrana de tecido conjuntivo fibroso, e com ausência de revestimento epitelial. Atualmente, após 2 anos do tratamento cirúrgico, não há evidências de recidiva da lesão.

Palavras-chave: Cisto ósseo simples; Mandíbula.

\section{SIMPLE BONE CYST - CLINICAL CASE REPORT}

\begin{abstract}
The World Health Organization classifies simple bone cyst as a non-neoplastic lesion related to bones, defined as an intraosseous cyst, which features a thin capsule. Its etiology remains unknown, and the most accepted explanation is related to the history of trauma. It is in most cases clinically asymptomatic and the diagnosis is often established through routine radiographic examination. The objective of this study is to report a case of a simple bone cyst in the left mandible region in a young patient underwent imaging
\end{abstract}


examinations for follow-up orthodontic treatment.The patient attended the Maxillofacial Traumatology Surgery Service showing circumscribed unilocular radiolucent lesion, in the left mandible region.Reported no significant swelling or pain symptoms. Excisional biopsy was performed and histopathological findings showed bone tissue associated with a thin membrane of connective tissue, and absence of epithelial lining. Today, after two years of surgical treatment, there is no evidence of recurrence.

keywords: Bone cyst simple; Jaw.

\section{INTRODUÇÃO}

O cisto ósseo simples (COS) é classificado pela Organização Mundial de Saúde (OMS) como uma lesão não neoplásica relacionada aos ossos. Foi inicialmente descrito por Lucas em 1929, sendo frequentemente relatado na literatura médica e odontológica desde então. Cisto ósseo traumático, cisto ósseo hemorrágico e cisto ósseo solitário são os termos mais comumente conhecidos. ${ }^{(1)}$

A etiopatogenia do $\operatorname{COS}$ não tem sido bem investigada, até o presente momento, para os casos mandibulares descritos. ${ }^{(2)}$ A grande maioria dos autores defende a teoria trauma-hemorragia, e adotam a nomenclatura de cisto ósseo traumático. ${ }^{(3)}$

Não existe uma concordância na literatura a respeito das características clínicas, como a preferência do gênero ou idade.(4) Muitas das ocorrências na área odontológica têm sido relatadas em jovens entre a primeira e segunda década de vida.(5) E quanto ao gênero, alguns autores afirmam haver predileção quanto ao sexo masculino. ${ }^{(6)}$

O efeito do COS sobre as corticais ósseas, vestibular e lingual é pequeno, e raramente se nota expansão.(7) Por outro lado, a lâmina dura pode ou não estar afetada, e reabsorções e/ou deslocamentos dentários podem ocorrer. ${ }^{(8)}$ Os sintomas são raros, e quando presente, é comum a dor, seguida de alteração em relação à sensibilidade dos dentes. ${ }^{(2)}$

O COS frequentemente aparece como uma área unilocular radiolúcida com limite bem definido, com ou sem linha esclerótica ao redor da lesão. ${ }^{(9)}$
Puricelli (1997) citado por Rodrigues e Estrela, ${ }^{(10)}$ asseguram que a análise da lesão pode ser feita através de radiografias periapicais, entretanto, por não abranger toda a extensão da lesão, são indispensáveis à radiografia panorâmica, e/ou a tomografia computadorizada. A ressonância magnética também pode ser solicitada e é útil para determinar a necessidade de realizar ou não a punção aspirativa.

O exame histopatológico de espécimes desta entidade patológica evidencia que a sua parede apresenta-se parcialmente revestida por uma fina camada de tecido conjuntivo, com alguma infiltração de células inflamatórias. (11) Outras evidências descritas na literatura são a presença de áreas vascularizadas, fibrina, eritrócitos e ocasionalmente células gigantes com a superfície óssea. ${ }^{(10)}$

A intervenção cirúrgica costuma ser indicada não apenas para certificar o diagnóstico da lesão como também pelo fato de que a simples exploração do cisto costuma ser o tratamento apropriado, apesar de alguns cistos ósseos desfazerem-se espontaneamente. ${ }^{(12)}$ As recidivas não são comuns, embora casos atípicos refratários ao tratamento cirúrgico convencional têm sido relatados. ${ }^{(13)}$

O objetivo deste artigo é relatar um caso de cisto ósseo simples de grande proporção em osso mandibular, em um paciente jovem e ressaltar as suas características clínicas, imaginológicas, histopatológicas e o tratamento adotado. Adicionalmente, 
pretende-se discutir os aspectos mais pertinentes descritos na literatura sobre este tipo de lesão.

\section{RELATO DE CASO}

Paciente I. S. B, 19 anos, sexo masculino, faioderma, residente no município de Feira de Santana, Bahia, Brasil, foi encaminhado ao Serviço de Cirurgia e Traumatologia Bucomaxilofacial de um Hospital Universitário, em função do aparecimento de uma imagem radiolúcida constatada em região mandibular esquerda através de exame imaginológico de rotina para acompanhamento do tratamento ortodôntico.

Durante a anamnese, o paciente não recordou qualquer tipo de trauma na região. Negou parestesia em região hemimandibular e sintomatologia no local acometido pela lesão. Ao exame extraoral, não se observou tumefação ou assimetria facial. Durante a inspeção intraoral, os testes de vitalidade pulpares térmicos e percussivos foram positivos, sendo observado um discreto aumento de volume na tábua óssea vestibular esquerda próxima à região do ângulo (Figura 1).

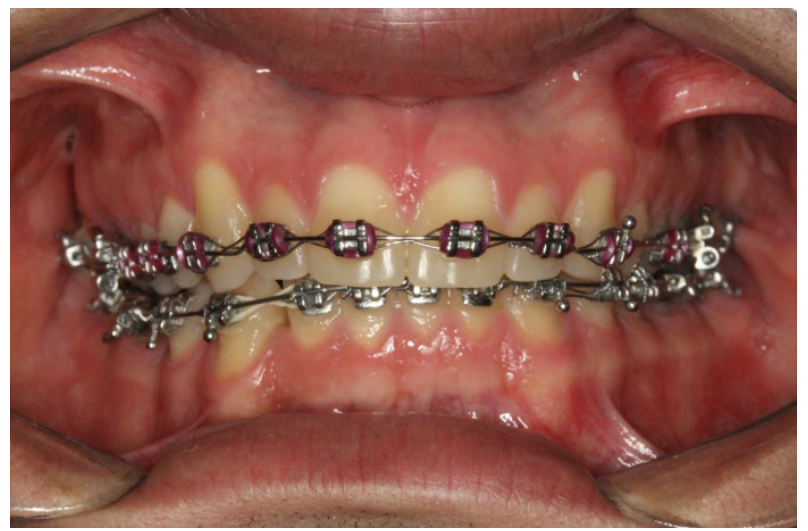

Figura 1 - Vista intraoral com discreto aumento de volume na tábua óssea vestibular em região mandibular esquerda

Ao exame radiográfico, a lesão se apresentava como uma loja radiolúcida unilocular, circunscrita, definida por um halo radiopaco que se estendia a partir da distal da unidade 38 , acometendo a região de ângulo. (Figura 2). Para uma melhor avaliação dos limites exatos da lesão em uma etapa pré-cirúrgica, a fim de determinar se havia ou não expansão da cortical óssea, foi solicitada a tomografia computadorizada, a qual apresentou aspectos imaginológicos similares àqueles descritos na radiografia panorâmica.

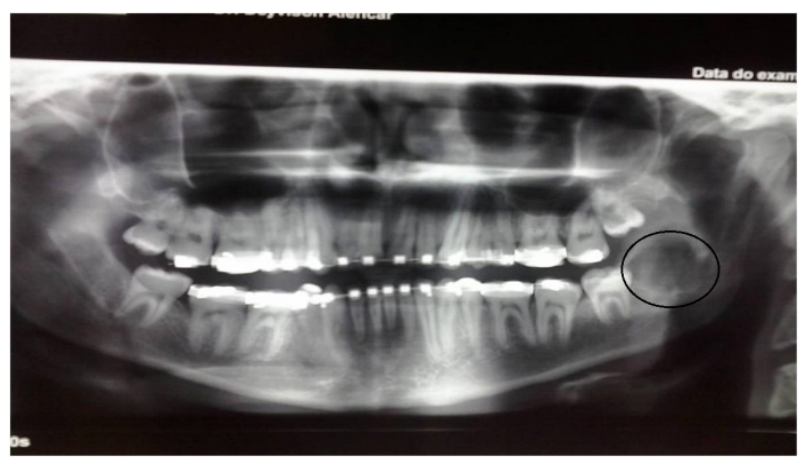

Figura 2 - Imagem radiolúcida unilocular próxima ao ângulo mandibular esquerdo 
Frente aos achados clínicos e imaginológicos, foi considerada hipótese diagnóstica de lesão de células gigantes central, ameloblastoma, cisto ósseo aneurismático e cisto ósseo traumático. Foram propostas biópsia excisional e exodontia da unidade dentária adjacente à lesão.

Com o paciente sob anestesia local, procedeu-se a exposição do sítio cirúrgico por meio da in- cisão intra-sulcular com relaxante distal e descolamento mucoperiosteal. Com a utilização de broca tronco-cônica 702, em baixa rotação, sob irrigação abundante de soro fisiológico $0,9 \%$, realizou-se perfuração possibilitando a punção do líquido no interior da câmara, e observando-se conteúdo serosanguinolento de coloração clara intra-lesional (Figura 3).

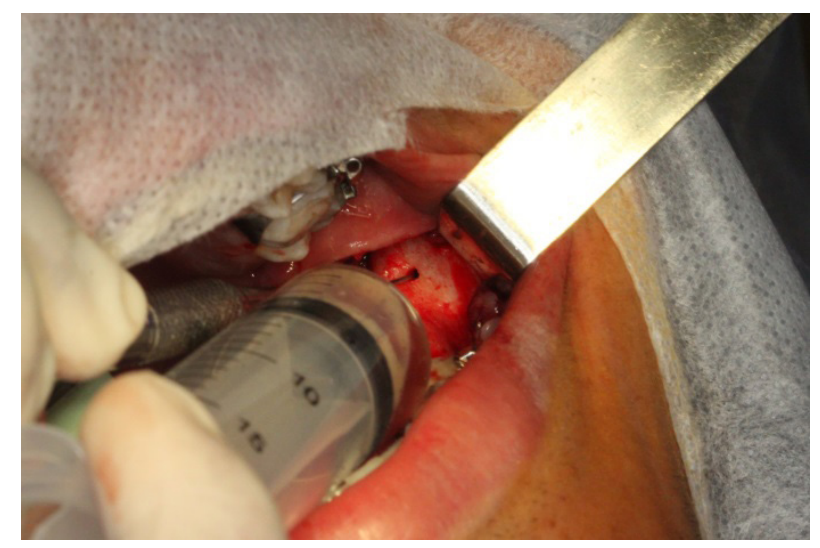

Figura 3 - Punção aspirativa realizada no período trans-cirúrgico

Em seguida, foi ampliada a osteotomia num formato ovalar com dimensões de $1,0 \times 1,5 \mathrm{~cm}$, da porção cortical do teto da lesão, na região do trígono retromolar, para visualização completa da loja cística. Observou-se uma nítida cavidade com paredes ósseas de aspecto íntegro, e ausência de epitélio no interior da lesão, fato este que confirmou a hipótese diagnóstica de cisto ósseo traumático (Figura 4). Parte da cortical foi removida e encaminhada para estudo anatomopatológico. Foi realizada curetagem do leito cirúrgico com regularização dos bordos, irrigação com soro fisiológico o,9\%, e sutura com fio nylon 4,0.

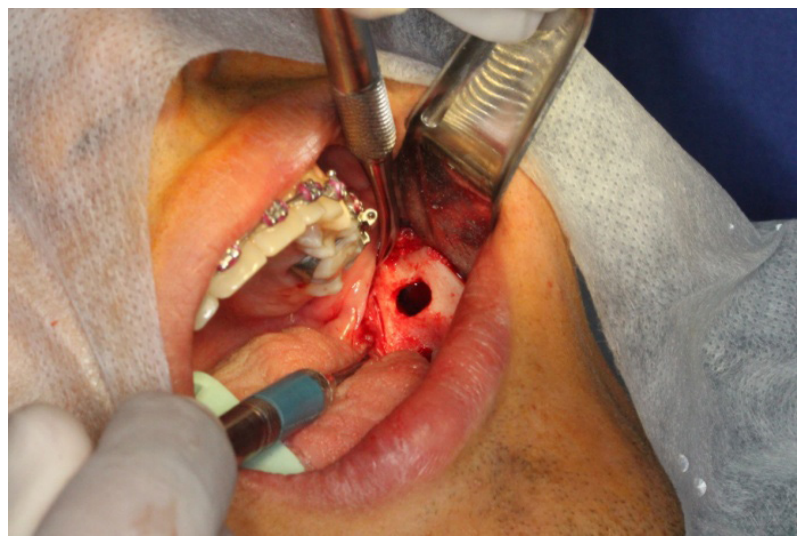

Figura 4 - Aspecto final da ampliação da osteotomia 
Durante o período pós-operatório foi instituída antibioticoterapia com Amoxicilina 50omg, uma cápsula a cada oito horas por cinco dias. Optou-se por realizar a cobertura antibiótica após a intervenção cirúrgica considerando-se a formação de hematoma intraósseo. Adicionalmente, foram prescritos, Dexametasona $4 \mathrm{mg}$, como anti-inflamatório, um comprimido à cada oito horas por três dias e o analgésico de escolha foi o Paracetamol $750 \mathrm{mg}$, um comprimido à cada seis horas por um dia. Além disso, o paciente foi orientado quanto ao uso de colutório oral à base de Digluconato de clorexidina a $0,12 \%(15 \mathrm{ml}), 24$ horas após a cirurgia, duas vezes ao dia, por sete dias.

O fragmento da biópsia foi encaminhado ao Serviço de Patologia Oral da EBMSP e o diagnóstico histopatológico foi de cisto ósseo simples (Figura 5 ). As secções teciduais evidenciaram lesão caracterizada pela ausência de revestimento epitelial e cavidade circundada por tecido conjuntivo denso.

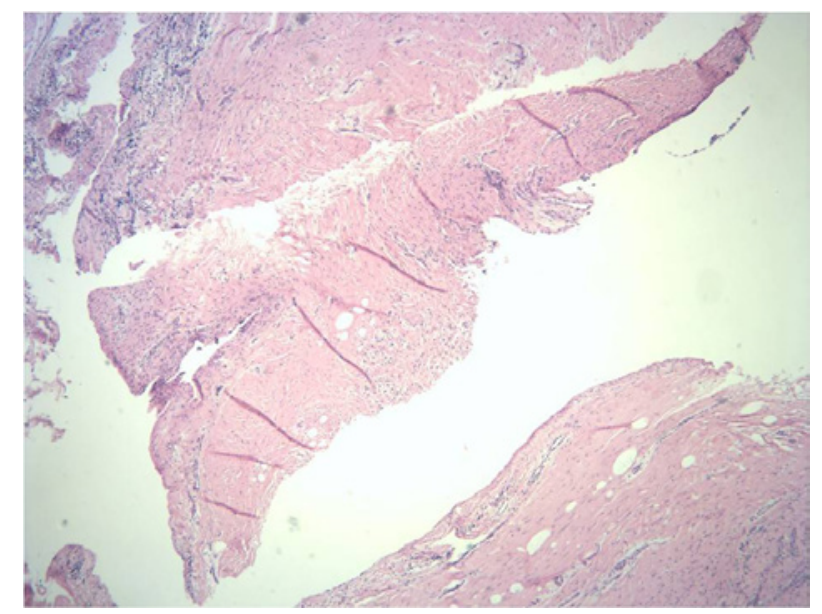

Figura 5 - Presença de tecido conjuntivo denso sem revestimento epitelial típico na lesão biopsiada. Hematoxilinaeosina, $100 \mathrm{X}$

Decorridos dois anos do procedimento cirúrgico, o paciente tem sido avaliado periodicamente e a tomografia computadorizada revelou imagem hiperdensa no interior da lesão, sugestiva de neoformação óssea, e aumento da espessura das corticais.

\section{DISCUSSÃO}

O cisto ósseo traumático é uma lesão cística maxilo-mandibular rara, ocorre com mais frequência na mandíbula, e de maneira genérica é denominado de cisto ou pseudocisto, uma vez que não apresenta características morfológicas de uma lesão cística como cápsula e revestimento epitelial próprio. ${ }^{(11)}$
No caso relatado, o paciente encontrava-se com 18 anos, gênero masculino e estava sob tratamento ortodôntico. A prevalência do cisto ósseo simples durante o tratamento ortodôntico se justifica pelo fato de que normalmente nesse período, os exames radiográficos solicitados para a obtenção da cefalometria são os primeiros exames de imagem realizados pelo paciente em região de face durante sua vida. ${ }^{(5)}$

Segundo Neville(6) uma agressão sobre o osso, insuficiente para provocar uma fratura, resulta em um hematoma intraósseo. Caso o hematoma não sofra organização e reparo, ele poderá liquefazer-se, promovendo um defeito cístico, teoria esta conhecida como trauma-hemorragia. No presente relato não foi possível associar o desenvolvimento da lesão a uma história de trauma, visto que durante 
a anamnese o paciente não relatou qualquer tipo de trauma associado à área de desenvolvimento da lesão.

O COS envolve as raízes dos dentes irrompidos. (7) Porém não reabsorvem a raiz e os dentes que parecem estar envolvidos na lesão são geralmente vitais, possuindo resposta positiva aos testes de vitalidade pulpar, observação feita no presente relato de caso haja vista a presença de vitalidade na unidade 3.8. ${ }^{(6)}$

O fato de se confirmar a presença de líquido no interior da cavidade óssea através de tomografia computadorizada e a ressonância magnética descarta a necessidade de punção aspirativa prévia. ${ }^{\left({ }^{14)}\right.}$ A ressonância magnética, exame radiográfico de alta complexidade, foi desconsiderada para avaliação da lesão, pois a radiografia panorâmica e a tomografia computadorizada se mostraram suficientes para condução do caso uma vez que já exibiam sinais sugestivos de cisto ósseo simples.

O diagnóstico da lesão é estabelecido através da associação da história clínica, dos exames físicos e imaginológico, e exploração cirúrgica. ${ }^{(1)}$ Apresenta-se como uma patologia de diagnóstico difícil, visto que existem várias lesões com características clínicas e radiográficas semelhantes a ela. (2) Com isso, a exploração cirúrgica também se constitui um importante recurso para a confirmação da hipótese diagnóstica de cisto ósseo simples. Logo, o tratamento mais preconizado é o cirúrgico. ${ }^{(12)}$ No caso relatado, o tratamento de eleição para o paciente foi o cirúrgico. A biópsia excisional foi precedida pela punção aspirativa. Embora não tenha sido realizada, a citopatologia a partir da PAAF é pouco invasiva e consiste num método importante para diagnóstico, além de ter grande valor para a diferenciação de lesões malignas e benignas, sendo essencial para uma terapia mais conservadora. ${ }^{(15)}$ A punção aspirativa revelou conteúdo serosanguinolento de coloração clara intra-lesional. Quando descoberta no início, a lesão geralmente contém sangue ou fluido serosanguinolento, mas com a sua evolução apresenta menor quantidade de fluido e gradualmente se torna vazia. ${ }^{(10)}$

Após a punção aspirativa foi realizada a curetagem da cavidade. A cirurgia por meio da curetagem estimula o sangramento e faz com que a cavidade seja tamponada e que ocorra neoformação óssea com a chegada de células indutoras da osteogênese. ${ }^{(2)}$ A exploração cirúrgica, além de ser um tratamento eficaz, permite a coleta de material para o exame histopatológico.

A confirmação do diagnóstico de cisto ósseo simples somente se deu quando da intervenção cirúrgica ao se evidenciar uma cavidade com paredes ósseas de aspectos íntegros e ausência de epitélio no interior da lesão. Porém, o diagnóstico definitivo do $\cos$ foi estabelecido através dos aspectos histopatológicos, os quais revelaram tecido ósseo associado a uma fina membrana de tecido conjuntivo frouxo, e com ausência de revestimento epitelial.

No relato de caso citado, seis meses após o procedimento cirúrgico o paciente retomou o tratamento ortodôntico e até o prezado momento, dois anos após a cirurgia, não apresenta sinal de recidiva da lesão. Foi observada formação de tecido ósseo na região e manutenção da vitalidade pulpar.

\section{CONSIDERAÇÕES FINAIS}

Apesar de frequentes relatos de casos de cisto ósseo simples, sua etiologia ainda é incerta, sendo a teoria de traumatismo pré-lesional a mais aceita. Esta lesão intraóssea requer um minucioso diagnóstico visto que patologias de curso clínico agressivo podem erroneamente serem confundidas com o COS. O cirurgião dentista deve solicitar exames radiográficos de rotina para que ele possa diagnosticar e tratar precocemente esta lesão. O tratamento é simples e consiste na própria exploração cirúrgica através da curetagem da lesão. O prognóstico é favorável e o paciente precisa ser acompanhado. 


\section{REFERÊNCIAS}

1. Dominguette AAS, Felizardo HMA, Dominguete MHL, Matos BHF, Oliveira LR, Dominguete PR. Cisto ósseo traumático em mandibula: relato de caso. Revista da Universidade do Rio Verde. 2O12;1O(2):308-13.

2. Paiva LCA, Menezes FS, Porto GG, Cerqueira PRF. Cisto Ósseo Simples- Relato de Caso. Rev. cir. traumatol. buco-maxilo-facial. 2011;1(2):1520.

3. Silva $A O$, Destri Júnior $A R$, Andrade AV, Santos LRA, Vilella OV. Localização inusitada de um cisto ósseo traumático: aspectos radiográficos. Odonto. 2011;19 (37): 99-105.

4. Lago AL, Cauás M, Pereira AM, Portela L. Cisto ósseo traumático em mandíbula: relato de caso. Rev. cir. traumatol. buco-maxilo-facial. 2006;6(2):23-8.

5. Ueda AS, Cuffari L. Cisto ósseo solitário: um estudo reunindo Ortopedia e Cirurgia e Traumatologia Bucomaxilofaciais. Revista Sociedade Brasileira Cirurgia e Traumatologia Buco. 2009;1(1):9-12.

6. Neville BW, Damm DD, Allen CM, Bouquot J. Patologia oral \& maxilo facial. $2^{a}$ ed. Rio de Janeiro: Guanabara Koogan; 2008.

7. Teixeira RG, Bueno CES, Miranda ME, Hofling RTB, Bussadori SK. Cistos ósseos simples. RGO. 2003; 51(4):243-48.
8. Castro AL, Paro MLC. Cisto ósseo traumático em mandíbula. RFO UPF. 2002; 7(1):39-42.

9. Xanthinaki AA; Choupis KI; Tosios K; Pagkalos VA; Papanikolaou SI. Traumatic bone cyst of the mandible of possible iatrogenic origin: a case report and brief review of the literature. Head Face Med. 2006, 2(40).

1O. Rodrigues CD, Estrela C. Traumatic bone cyst suggestive of large apical periodontitis. J Endod. 2008; 34(4):484-89.

11. Sarmento DJS, Pinto TCA, Pinto AKA, Luna AHB, Godoy GP. Cisto ósseo traumático. Relato de caso clínico. Rev. ABO nac. 2010;18(1):23942.

12. Jesus VAD, Santos TS, Fernandes AV, Santos JS. Cisto ósseo traumático- relato de caso. Rev. cir. traumatol. buco-maxilo-facial. 2010:10(4):2730.

13. Dornelles Junior NB. Cisto ósseo traumático: relato de caso de um caso refratário ao tratamento cirúrgico convencional [monografia]. Porto Alegre: UFRGS; 2010.

14. Azevedo RA, Marques JAF, Soares SS, Carneiro JRB, Santana SI. Cisto ósseo simples: relato de casos clínicos. BCl 2002; 9(34):139-43.

15. Robaina TF, Coutinho ACA, Valladares CP, Dias EP, Lourenço SQC. Correlação entre os diagnósticos citopatológicos e histopatológicos das lesões da mucosa oral após a punção aspirativa por agulha fina. Rev. Col. Bras. Cir. 2007; 34(5):285-89. 